\title{
Exploring Mobile Learning Apps for medical students and health care professionals
}

\author{
Laura Briz-Ponce \\ Research Institute for Educational Sciences (IUCE) \\ University of Salamanca \\ (+34) 923294546 \\ laura.briz@usal.es \\ Juan Antonio Juanes-Méndez \\ Research Institute for Educational Sciences (IUCE) \\ University of Salamanca \\ (+34) 923294546 \\ jajm@usal.es \\ Francisco José García-Peñalvo \\ Research Institute for Educational Sciences (IUCE) \\ University of Salamanca \\ (+34) 923294546 \\ fgarcia@usal.es
}

\begin{abstract}
There is an increasing number of Apps available in the different marketplaces. Most part of them are categorized according to the criterion of the developer, which may make this classification inaccurate sometimes. The object of this paper is to provide some insights regarding the use of health Apps among undergraduate medical students, residents, specialists and medical teachers. This paper also list the Apps most used and the reasons claimed by these participants in case they do not used them. The methodology used to collect the data was a noninstrumental design based on a questionnaire to retrieve quantitative and qualitative data. The final number of participants involved in this research was 124 . The results obtained with this research reveal that $38 \%$ of them use this type of Apps. Besides, residents, specialists and medical teachers use more medical Apps than students. Finally, the two main reasons of not using them stated by the participants were the unawareness and the lack of necessity.
\end{abstract}

\section{CCS Concepts}

- Human-centered computing Smartphones

- Human-centered computing Tablet computers

- Applied computing Consumer health

- Applied computing Health informatics

Keywords

Medical education; e-learning; m-learning; smartphones; tablets; apps; e-health; m-health.

\section{INTRODUCTION}

One of the key aspects of medical education is how the new technologies are impacting on medicine field. These new trends provide new resources to students to access information and courses' content from any place. Besides, if the mobile devices are added, the accessibility, flexibility and the ubiquity are enhanced [1]. In this environment, new words are e-health and m-health emerged in our society.

Telemedicine is a part of the e-health field and this discipline allows the interchange of information, images and laboratory results. Besides, this field is very wide and encompass not only the patients' health but also the management, systems and process around the public health [2].

On the other hand, the article published by Istepanian [3] reveals that m-health presents the evolution of e-health from the traditional platforms and systems to the use of mobile devices.

The growth of Smartphones was a revolution in the mobile world and due to it, a new business model appeared based on mobile applications (Apps). These Apps could be defined as programs running on mobile devices that provide them advanced functionalities. The place that stores the different Apps is called marketplace. According to the operating system, it is possible to find different ones. The most popular are the Apple Store (owned by Apple), Play Store (owned Google). There are more than two million of Apps in each of them, which shows the increasing demand of them by users.

In addition, Apps are categorized in these marketplaces. One new category is called health, where it is possible to find m-health Apps. This field is causing a great demand from users, because of that, the number of this type of Apps is increasing. 
It is extremely complicated to know the exact number of Apps for one category, as they are changing every day. Some experts considered that the number of health Apps were no less than 40.000 [4,7], and around 37.462 are included in App Store ${ }^{1}$.

Currently, there are more than 160.000 m-health Apps and 103.000 if the Apps included in different marketplaces are deleted [5]. According to that report, there are around 70.000 m-health Apps in App Store and Play Store.

This paper shows a brief overview of the medical Apps used the most by medical participants and it is divided in three sections. First of all, it describes the methodology used, the type of participants involved in this research. The second section explains the main results obtained with the research and finally the third section show the discussion and the conclusions drawn of this analysis.

\section{METHODOLOGY}

The methodology used in this research was non-experimental transactional and the data collected were both quantitative and qualitative. The design utilized was descriptive and the instrument employed was a survey with 19 items in order to retrieve information regarding the participants' basic characteristics and experience with mobile devices. This survey added one open question in order to obtain which type of Apps used the most and give the opportunity to write the medical Apps utilized and the reasons for not using them.

\subsection{Participants}

All the survey respondents were voluntary and the data collected were completely anonymous. Different profiles of contributors were used in it: undergraduate students from Medical School, residents, specialists and medical teachers. The final cohort was 124.

The resulting descriptive statistics are described in Table 1, which shows that the percentage of profile of participants was very similar but there was a major proportion of female participants than male participants $(63.7 \%$ female, $36 \%$ male). The reason could be the growing tendency of women signed up in Medical Schools. Approximately, since 1998, the proportion of new female students in Medical Schools in Spain is roughly $65 \%-71 \%[6,8]$.

Table 1. Descriptive statistics of participants' basic characteristics

\begin{tabular}{|c|c|c|c|}
\hline Variable & Description & fre & \\
\hline Gender & $\begin{array}{l}\text { Male } \\
\text { Female }\end{array}$ & & $\begin{array}{l}36.3 \% \\
63.7 \%\end{array}$ \\
\hline Profile & $\begin{array}{l}\text { Student } \\
\text { Medical Resident } \\
\text { Medical Specialist } \\
\text { Medical teachers }\end{array}$ & $\begin{array}{l}61 \\
24 \\
21 \\
18\end{array}$ & $\begin{array}{l}49.2 \% \\
19.4 \% \\
16.9 \% \\
14.5 \%\end{array}$ \\
\hline Range of age & $\begin{array}{l}\text { From } 18 \text { to } 25 \\
\text { From } 26 \text { to } 35 \\
\text { From } 36 \text { to } 45 \\
\text { From } 46 \text { to } 55 \\
+55\end{array}$ & $\begin{array}{l}60 \\
28 \\
6 \\
23 \\
7\end{array}$ & $\begin{array}{l}48.4 \% \\
22.6 \% \\
4.8 \% \\
18.5 \% \\
5.6 \%\end{array}$ \\
\hline Ownership & $\begin{array}{l}\text { Only Smartphone } \\
\text { Only Tablet } \\
\text { Smartphone and } \\
\text { Tablet } \\
\text { Neither Smartphone } \\
\text { nor tablet }\end{array}$ & $\begin{array}{l}58 \\
1 \\
58 \\
7\end{array}$ & $\begin{array}{l}46.8 \% \\
0.8 \% \\
46.8 \% \\
5.6 \%\end{array}$ \\
\hline
\end{tabular}

The dominant age presented in the sample was ranging from 18 to 35 years with a $71 \%$ of the participants. It is also important to stress that the most part of the participants (in fact, 94.4\%) reported they owned a Smartphone, a tablet device or of both of them [9].

\section{RESULTS}

\subsection{Type of Apps}

The survey also collected data regarding the experience of participants with mobile devices and the descriptive statistics are shown in Table 2.

On average, the Smartphone is the mobile device that the participants used the most with Apps. The most frequent time of use is between one and two hours per day.

\footnotetext{
${ }^{1} \mathrm{http}: / /$ www.pocketgamer.biz/metrics/app-store/categories/
} 
According to the results, each participant selected on average 3.5 type of categories of Apps. Besides, the Figure 1 describes more in detail the percentage of participants that have used one of Apps categorized within the medical or health one.

It is important to highlight that residents were the participants that have used them the most.

Table 2. Descriptive statistics of participants' experience

\begin{tabular}{|l|l|l|l|}
\hline Variable & Description & freq. & \% \\
\hline Use of Apps on & Less 1h/day & 1 & $0.8 \%$ \\
Smartphone & $1-2 \mathrm{~h} /$ day & 63 & $50.8 \%$ \\
& $3-4 \mathrm{~h} /$ day & 16 & $12.9 \%$ \\
& More 4h/day & 28 & $22.6 \%$ \\
& None & 16 & $12,9 \%$ \\
\hline Use of Apps on & Less 1h/day & 0 & $0 \%$ \\
Tablet & $1-2 \mathrm{~h} /$ day & 41 & $33.1 \%$ \\
& $3-4 \mathrm{~h} /$ day & 5 & $4.0 \%$ \\
& More 4h/day & 1 & $0.8 \%$ \\
& None & 70 & $56.5 \%$ \\
& N/A & 7 & $5.6 \%$ \\
\hline Type of Apps & Entertainment & 88 & $71.0 \%$ \\
& News & 33 & $26.6 \%$ \\
& Social Networks & 84 & $67.7 \%$ \\
& Mail & 56 & $45.2 \%$ \\
& Games & 64 & $51.6 \%$ \\
& Medical Apps & 41 & $33.1 \%$ \\
& Educative Medical Apps & 31 & $25 \%$ \\
& Other & 20 & $16.1 \%$ \\
& None & 9 & $7.3 \%$ \\
\hline
\end{tabular}

The total percentage of participants that have used any medical App is 37,9\%. In order to calculate it, it was necessary to eliminate the participants that have used both type of Apps.

In fact, considering the profile of participants, the results reveal that $6 \%$ of participants were students that have used any type of Apps. Regarding residents, the percentage was $16 \%$. As for both specialists and medical teachers the percentage was $8 \%$.

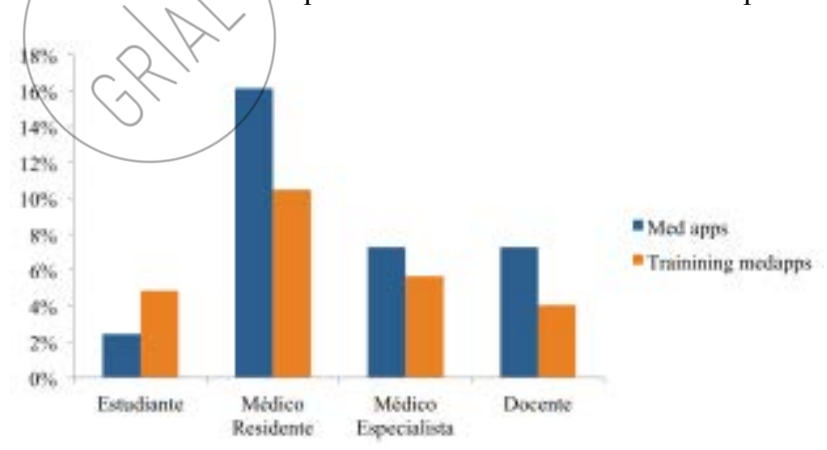

Figure 1. Percentage of participants that have used any medical App

\subsection{List of Apps}

Another interesting data that the participants should answer was the medical App that they used the most. Among all participants, only 38 of them answered that they have used any medical App (18\% of them were students). According to the results, it was possible to list them as it is shown in Table 3.

Table 3. List of the most used Apps by participants

\begin{tabular}{|l|r|r|}
\hline App & Frequency & \% \\
\hline Vademecum & 6 & $16 \%$ \\
\hline Anatomy & 5 & $13 \%$ \\
\hline
\end{tabular}




\begin{tabular}{|c|c|c|}
\hline 3D_Brain & 4 & $11 \%$ \\
\hline Anatomical Atlas & 2 & $5 \%$ \\
\hline Dictionary & 2 & $5 \%$ \\
\hline Gray's Anatomy & 2 & $5 \%$ \\
\hline Medmecum & 2 & $5 \%$ \\
\hline medscape & 2 & $5 \%$ \\
\hline No remember & 2 & $5 \%$ \\
\hline Information pamphlet & 2 & $5 \%$ \\
\hline Radiology & 2 & $5 \%$ \\
\hline Skeleton & 2 & $5 \%$ \\
\hline Visual Anatomy & 2 & $5 \%$ \\
\hline 3d4d_Medical & 1 & $3 \%$ \\
\hline Acos & 1 & $3 \%$ \\
\hline Ajnr MoctNet & 1 & $3 \%$ \\
\hline Apps of Scientific Societies & 1 & $3 \%$ \\
\hline Children's Atlas & 1 & $3 \%$ \\
\hline Atlas Visible Body & 1 & $3 \%$ \\
\hline Daily Doctor & 1 & $3 \%$ \\
\hline Doses & 1 & $3 \%$ \\
\hline dsm-iv-tr & 1 & $3 \%$ \\
\hline e-Anatomy & 1 & $3 \%$ \\
\hline EcoAtlas & 1 & $3 \%$ \\
\hline Therapeutic strategies & 1 & $3 \%$ \\
\hline Pharmacoterapy & 1 & $3 \%$ \\
\hline Phisiology & 1 & $3 \%$ \\
\hline GoodReader & 1 & $3 \%$ \\
\hline Guidelines & 1 & $3 \%$ \\
\hline Harrinson & 1 & $3 \%$ \\
\hline Listadocompleto & 1 & $3 \%$ \\
\hline MedCalc & 1 & $3 \%$ \\
\hline MedicalBasics, Essential Medicina & 1 & $3 \%$ \\
\hline mipresion & 1 & $3 \%$ \\
\hline MRI & 1 & $3 \%$ \\
\hline ncen & 1 & $3 \%$ \\
\hline Netter & 1 & $3 \%$ \\
\hline pubmed & 1 & $3 \%$ \\
\hline qxcalculate & 1 & $3 \%$ \\
\hline Realitiy of Afib & 1 & $3 \%$ \\
\hline sepsis & 1 & $3 \%$ \\
\hline Shoulderdoc, Ultrasound & 1 & $3 \%$ \\
\hline Visible Body, VisiblePatient & 1 & $3 \%$ \\
\hline
\end{tabular}

The App most used was Vademecum, followed by Anatomy and 3D_Brain. It is important to mention that most part of the Apps used by medical participants were related with Anatomy (Dictionaries, Atlas, etc.).

The Figure 2 represents this list with a graphic more visual. In order to develop this image, was necessary to use the program NVIVO v21. This tool is very common for qualitative studies and provides the instruments to make a revision of words frequency. 


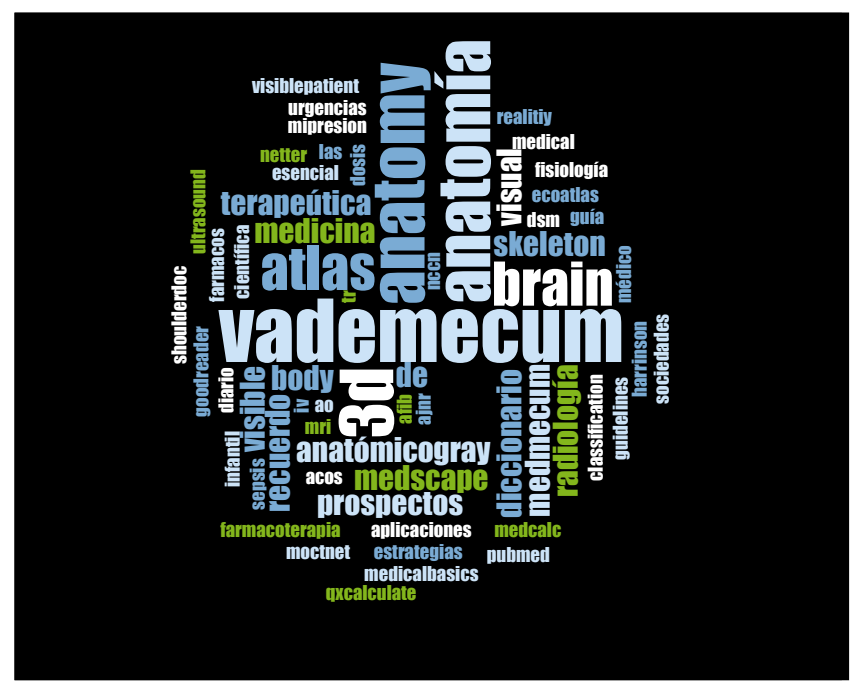

Figure 2. List of Apps from NVIVO program

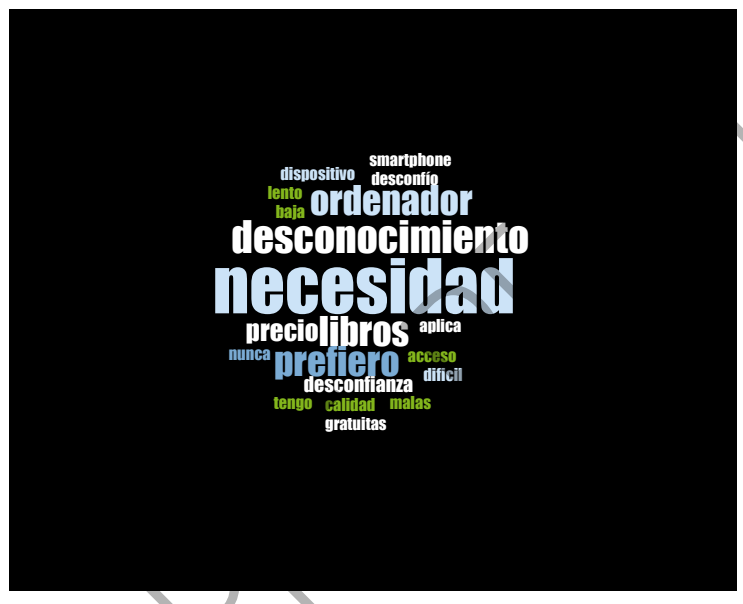

Eigure 3. Graphic of reasons for not using Medical Apps

\subsection{Reasons for no using}

The survey distributed to the participants also collected information of the reasons for no using this type of Apps. This information is very important to bring into light the problems-or challenges that it is necessary to overcome in order to promote the potential new tools of mobile learning.

In this case, $69 \%$ of participants reported that they have not used any Medical App. Most part of them (63\%) of them were students. However only $58 \%$ of the total wrote the reason.

The Table 4 shows the reasons reported by the participants. As it is possible to see, the two main reasons were the no necessity (42\%) and the unawareness $(21 \%)$.

In this case, the NVIVO program is also used in order to obtain the visual graphic with the examination of frequency words, which is depicted in Figure 3.

The third reason revealed by participants was the preference of other resources as books or laptops. They considered them as easy and practical use to study.

Table 4. List of reasons reported by participants

\begin{tabular}{|l|c|c|}
\hline \multicolumn{1}{|c|}{ Reason } & Frequency & $\mathbf{\%}$ \\
\hline No necessity & 16 & $42 \%$ \\
\hline Unawareness & 8 & $21 \%$ \\
\hline Preference Book & 7 & $18 \%$ \\
\hline Preference Laptop & 7 & $18 \%$ \\
\hline Price & 4 & $11 \%$ \\
\hline
\end{tabular}




\begin{tabular}{|l|l|l|}
\hline Mistrust & 3 & $8 \%$ \\
\hline Access & 1 & $3 \%$ \\
\hline Quality & 1 & $3 \%$ \\
\hline Technical issues & 1 & $3 \%$ \\
\hline Slow device & 1 & $3 \%$ \\
\hline They are bad & 1 & $3 \%$ \\
\hline
\end{tabular}

\section{DISCUSION AND CONCLUSION}

The data shows as result of this research bring into light that the use of medical Apps as potential tools for learning is not very extended among students.

There are other authors that have listed a number of Apps for different disciplines basically making a search from different marketplaces. For example, Chemistry [10], clinical systems [11], Anatomy [12] or microbiology [13]. However, this paper is not focused in any concrete field, only any type of Apps that the participants used the most in Medicine.

It is important to notice that the Apps related with Anatomy were the ones more frequently used. The Vademecum is an App focused on Pharmacology. It is a free App, although some contents must be accessed with an annual subscription, which also shows that type of Apps with medical information could be considered very important for the participants.

Another important insight that could be retrieved from this research is the reasons for not using them. There are some studies that have analyzed the impact of Apps in learning [14-17] obtaining that although the performance scores were better with the participants that have used Apps versus the group that have not used them, it is necessary to involve the institutions and organisms to support the integration of these tools and make the adoption in the pedagogical curriculum be a reality.

\section{ACKNOWLEDGMENTS}

This research work is made within University of Salamanca PhD Programme on Education in the Knowledge Society. This research has been funded by the call DOCTOR TCUE to support finishing doctoral Thesis focused in turning research results into concrete products or services, belonging to the Plan TCUE 2015-2017 from University of Salamanca and co-funded by European Regional Development Fund (ERDF) and Regional Government of Castilla y León (Spain).

\section{REFERENCES}

[1] Gikas, J., and Grant, M. M. 2013. Mobile computing devices in higher education: Student perspectives on learning with cellphones, smartphones \& social media. The Internet and Higher Education, 19, 18-26. http://doi.org/10.1016/j.iheduc.2013.06.002

[2] Healy, J.-C. 2008. Implementing e-health in developing countries: Guidance and principles. Ginebra, Suiza: International Telecommunication Union.

[3] Istepanian, R. S. H., Jovanov, E., and Zhang, Y. T. 2004. Guest Editorial Introduction to the Special Section on M-Health: Beyond Seamless Mobility and Global Wireless Health-Care Connectivity. IEEE Transactions on Information Technology in Biomedicine, 8(4), 405-414. http://doi.org/10.1109/TITB.2004.840019

[4] Kamel Boulos, M. N., Brewer, A. C., Karimkhani, C., Buller, D. B., and Dellavalle, R. P. 2014. Mobile medical and health apps: state of the art, concerns, regulatory control and certification. Online Journal of Public Health Informatics, 5(3), 1-23. http://doi.org/10.5210/ojphi.v5i3.4814

[5] Research2Guidance. 2015. mHealth App Developer Economics 2015. Berlín, Alemania: research2guidance.

[6] Instituto Nacional de Estadística. 2012. Estadistica de Enseñanza Universitaria-alumnado matriculado por Universidad, sexo y estudio. Madrid, España: Instituto Nacional de Estadística.

[7] Pelletier, S. G. 2012. Explosive Growth in Health Care Apps Raises Oversight Questions -. Association of American Medical Colleges Reporter.

[8] Briz-Ponce, L., Juanes-Méndez, J. A., and García-Peñalvo, F. J.. 2016. The role of Gender in Technology Acceptance for Medical Education. In M. M. Cruz-Cunha, I. M. Miranda, R. Martinho, and R. Rijo (Eds.), Encyclopedia of E-Health and Telemedicine (Vol. II, pp. 1013-1027). Hershey, PA: IGI Global.

[9] Briz-Ponce, L., Juanes-Méndez, J. A., and García-Peñalvo, F. J.. 2014. First Approach of Mobile Applications Study for Medical Education purposes. In Proceedings of the Second International Conference on Technological Ecosystems for Enhancing Multiculturality-TEEM14 (pp. 647-651). New York, USA: ACM New York. http://doi.org/10.1145/2669711.2669968

[10] Libman, D., and Huang, L. 2013. Chemistry on the Go: Review of chemistry apps on smartphones. Journal of Chemical Education, 90(3), 320-325. http://doi.org/10.1021/ed300329e

[11] Martínez-Pérez, B., De La Torre-Díez, I., López-Coronado, M., Sainz-De-Abajo, B., Robles, M., and García-Gómez, J. M. 2014. Mobile clinical decision support systems and applications: A literature and commercial review. Journal of Medical Systems, 38(4), 110. http://doi.org/10.1007/s10916-013-0004-y

[12] Lewis, T. L., Burnett, B., Tunstall, R. G., and Abrahams, P. H. 2014. Complementing anatomy education using three-dimensional anatomy mobile software applications on tablet computers. Clinical Anatomy, 27(3), 313-320. http://doi.org/10.1002/ca.22256

[13] Visvanathan, A., Hamilton, A., and Brady, R. R. W. 2012. Smartphone apps in microbiology-is better regulation required?. Clinical 
Microbiology and Infection, 18(7), 218-220. http://doi.org/10.1111/j.1469-0691.2012.03892.x

[14] Holland, J. 2014. Mobile Learning Apps: Evaluating Instructional Needs. In X. Xu (Ed.), Interdisciplinary Mobile Media and Communications: Social, Political, and Economic Implications (pp. 26-47). USA: IGI Global.

[15] Morris, R., Javed, M., Bodger, O., Gorse, S. H., and Williams, D. 2014. A comparison of two smartphone applications and the validation of smartphone applications as tools for fluid calculation for burns resuscitation. Burns, 40(5), 826-834. http://doi.org/10.1016/j.burns.2013.10.015

[16] Briz-Ponce, L., Juanes-Méndez, J. A., García-Peñalvo, F. J., and Pereira, A. 2016. Effects of Mobile Learning in Medical Education: a Counterfactual Evaluation. Journal of Medical Systems, 40(6), 1-6. http://doi.org/10.1007/s10916-016-0487-4

[17] Briz-Ponce, L., Juanes-Méndez, J. A., and García-Peñalvo, F. J.. 2015. Synopsis of discussion session on defining a new quality protocol for medical apps. In Proceedings of the Third International Conference on Technological Ecosystems for Enhancing Multiculturality-TEEM15. New York: ACM.

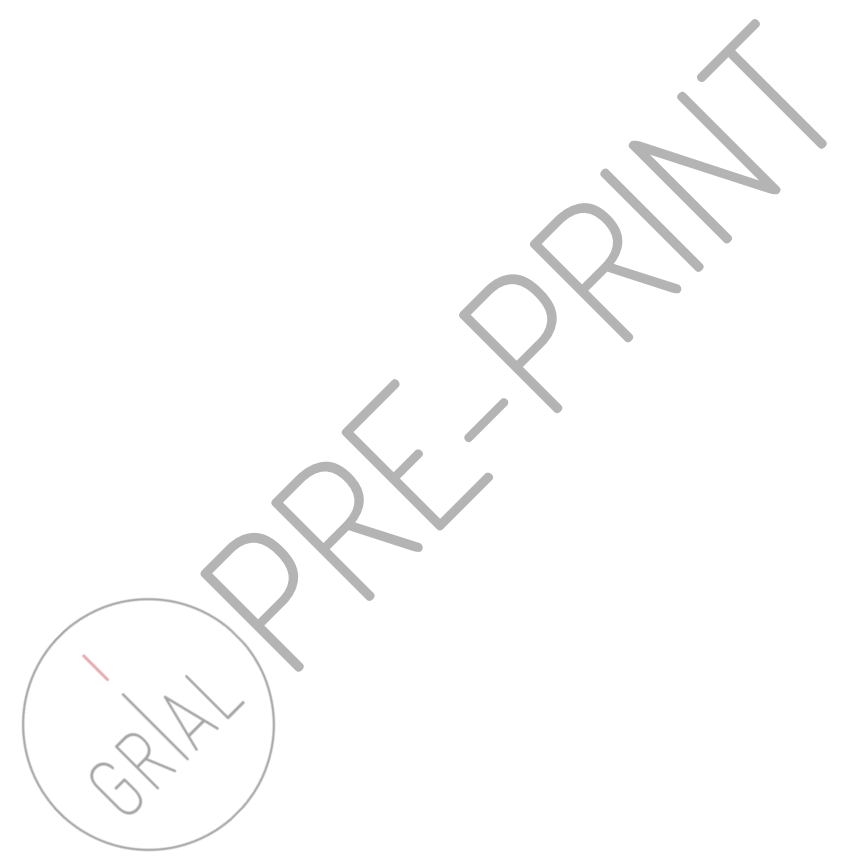

